\title{
A single nucleotide polymorphism in the Epstein-Barr virus genome is strongly associated with a high risk of nasopharyngeal carcinoma
}

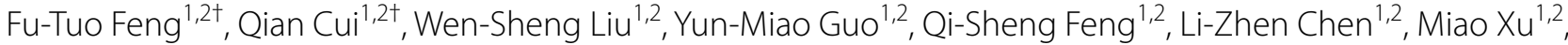 \\ Bing Luo ${ }^{3}$, Da-Jiang Li ${ }^{1,2}$, Li-Fu Hu ${ }^{4}$, Jaap M. Middeldorp ${ }^{5}$, Octavia Ramayanti ${ }^{5}$, Qian Tao ${ }^{6}$, Su-Mei Cao ${ }^{1,7}$, \\ Wei-Hua Jia ${ }^{1,2}$, Jin-Xin Bei ${ }^{1,2^{*} \ddagger}$ and Yi-Xin Zeng ${ }^{1,2^{*} \ddagger}$
}

\begin{abstract}
Background: Epstein-Barr virus (EBV) commonly infects the general population and has been associated with nasopharyngeal carcinoma (NPC), which has a high incidence in certain regions. This study aimed to address how EBV variations contribute to the risk of NPC.

Methods: Using logistic regression analysis and based on the sequence variations at EBV-encoded RPMS1, a multistage association study was conducted to identify EBV variations associated with NPC risk. A protein degradation assay was performed to characterize the functional relevance of the RPMS1 variations.

Results: Based on EBV-encoded RPMS1 variations, a single nucleotide polymorphism (SNP) in the EBV genome (locus 155391: G>A, named G155391A) was associated with NPC in 157 cases and 319 healthy controls from an NPC endemic region in South China $[P<0.001$, odds ratio $(\mathrm{OR})=4.47,95 \%$ confidence interval $(\mathrm{Cl}) 2.71-7.37]$. The results were further validated in three independent cohorts from the NPC endemic region $(P<0.001, \mathrm{OR}=5.20,95 \% \mathrm{Cl}$ 3.18-8.50 in 168 cases vs. 241 controls, and $P<0.001, \mathrm{OR}=5.27,95 \% \mathrm{Cl} 4.06-6.85$ in 726 cases vs. 880 controls) and a non-endemic region ( $P<0.001, \mathrm{OR}=7.52,95 \% \mathrm{Cl} 3.69-15.32$ in 58 cases vs. 612 controls). The combined analysis in 1109 cases and 2052 controls revealed that the SNP G155391A was strongly associated with NPC $\left(P_{\text {combined }}<0.001\right.$, $\mathrm{OR}=5.27,95 \% \mathrm{Cl}$ 4.31-6.44). Moreover, the frequency of the SNP G155391A was associated with NPC incidence but was not associated with the incidences of other EBV-related malignancies. Furthermore, the protein degradation assay showed that this SNP decreased the degradation of the oncogenic RPMS1 protein.
\end{abstract}

Conclusions: Our study identified an EBV variation specifically and significantly associated with a high risk of NPC. These findings provide insights into the pathogenesis of NPC and strategies for prevention.

Keywords: Epstein-Barr virus, Nasopharyngeal carcinoma, RPMS1, Association

\section{Background}

Nasopharyngeal carcinoma (NPC) is a malignancy with a marked geographic distribution and ethnic tendencies, occurring with high frequencies in South China,

\footnotetext{
*Correspondence: beijx@sysucc.org.cn; zengyx@sysucc.org.cn

${ }^{\dagger}$ Fu-Tuo Feng and Qian Cui authors equally contributed to the work

${ }^{\ddagger} J$ Jin-Xin Bei and Yi-Xin Zeng authors jointly directed this work

1 Sun Yat-sen University Cancer Center, State Key Laboratory of Oncology

in South China, Collaborative Innovation Center for Cancer Medicine,

Guangzhou 510060, Guangdong, P. R. China

Full list of author information is available at the end of the article
}

Southeast Asia, North Africa, and Alaska [1]. The etiology of NPC is complex, involving multiple factors such as genetic susceptibility, Epstein-Barr virus (EBV) infection, and environmental factors [2-4]. The known association between EBV and NPC was mainly driven by findings that EBV-encoded molecules, some of which are potentially oncogenic, were consistently observed in nearly all NPC tissues and that EBV serological markers, including viral DNA load and antibodies against viral antigens, were associated with NPC diagnosis and prognosis [5-7]. 
EBV infection is ubiquitous, affecting more than 95\% of the worldwide population; EBV was also the first virus identified in a human tumor, i.e., Burkitt's lymphoma. EBV has also been closely associated with Hodgkin's lymphoma and some gastric cancers [8]. The incidences of these malignancies show remarkably different geographic distributions [9], which is paradoxical in comparison to the widespread infection with EBV. Moreover, sequence diversity in EBV genes has been demonstrated among the general population and in different tumor types $[10,11]$. These results suggest the hypothesis that there might be some disease-specific EBV subtypes preferentially hazardous to certain populations, making them more prone to certain specific diseases such as NPC.

A number of studies have reported attempts to identify NPC-specific EBV subtypes using restriction fragment length polymorphism analysis and DNA sequencing based on the sequence variations of EBV genes. These genes were consistently observed in NPC tissues, including EBV nuclear antigens (EBNAs), latent membrane proteins ( $L M P 1$ and $L M P 2)$, and EBVencoded small nuclear RNAs (EBERs) [9, 10, 12]. EBV can be characterized as Type 1 (Type A) or Type 2 (Type B) based on the sequence diversity of EBNA2 and EBNA3s $[13,14]$. Type 1 EBV strains are more common worldwide, whereas Type 2 is equally prevalent in parts of Africa [15-17]. Based on an amino acid polymorphism at position 487 of $E B N A-1$, EBV has been classified into five strains: P-ala (B95-8 prototype), P-thr, V-val, V-leu, and V-pro [18-20]. V-val was detected almost exclusively in Chinese populations, whereas $\mathrm{P}$-ala and P-thr were detected with a high prevalence in healthy individuals from both Chinese and non-Chinese populations $[21,22]$. Based on the nucleotide sequence variations at the LMP1 C-terminus, EBV can be separated into seven strains: China 1 , China 2, Med, China 3, Alaskan, NC, and B95-8 [23]. Among the Asian isolates, China 1 and B95-8 were identified in healthy subjects, and China 1 and China 2 were found in NPC patients [23]. It has been reported that the Cantonese population is susceptible to the predominant China 1 strain in the NPC endemic region in China [24]. These investigations suggested that there were relatively stable genomic variations in EBV and that different subtypes might exist in different geographic regions.

To further identify EBV variations linked closely to NPC risk, we conducted a pilot association analysis on several important EBV-encoded genes, including $L M P 1$, $E B N A 1$, and the BamHI-A rightward transcripts (BARTs) family, starting from NPC cases and healthy controls in the Cantonese population in South China. The most striking finding is that a single nucleotide polymorphism (SNP) in the EBV-encoded RPMS1 gene (locus 155391:
G>A, named G155391A) is significantly associated with NPC incidence.

Previous studies have demonstrated that the BARTs family members are abnormally expressed in most NPC tissues and might contribute to NPC development [25, 26]. RPMS1 encodes a major part of the mRNA of the $B A R T s$ family and is regularly transcribed in NPC tissues $[26,27]$. In particular, abundant RPMS1 mRNA was detected in NPC tissues and cell lines [28]. Considering the potential roles of RPMS1 in NPC oncogenesis [25, 27, 29 ], we speculated that the sequence variation of RPMS1 might contribute to the incidence variations of NPC among different geographic regions and ethnic groups. Therefore, we conducted a large-scale case-control study using a multistage design to identify the association between RPMS1 variations and NPC risk.

\section{Methods}

\section{Subjects and samples}

For the pilot study, 60 paired NPC cases and healthy controls were recruited from Sun Yat-sen University Cancer Center (SYSUCC) between October 2005 and October 2007. Throat washing (TW) samples were subjected to polymerase chain reaction (PCR) and direct DNA sequencing to screen for genomic variations exhibiting significant differences between the cases and controls.

The discovery stage involved 346 sporadic Cantonese NPC patients and 448 healthy subjects (Data_GD1), recruited from SYSUCC and the First Affiliated Hospital of Sun Yat-sen University ( $1^{\text {st }}$ AH-SYSU), Guangdong Province, an NPC endemic region in South China, between October 2005 and October 2007.

In the validation stage, three independent sample cohorts were collected from the NPC endemic and nonendemic regions in China between October 2008 and June 2013. The first group consisted of $222 \mathrm{TW}$ samples from sporadic NPC patients and 315 TW samples from healthy subjects from the SYSUCC and the 1st AHSYSU (Data_GD2). The second group consisted of 1065 TW samples from sporadic NPC patients and 1161 TW samples from healthy subjects from the local community hospitals in Guangdong Province (Data_GD3). The third group consisted of 36 tumor biopsy (TB) samples and 66 TW samples from NPC patients from the Affiliated Hospital of Qingdao University (AH-QDU) and Shandong Province Cancer Center, in addition to 1543 TW samples from healthy subjects from the physical examination centers at local community hospitals in Shandong Province, a NPC non-endemic region in North China (Data_ SD) (Table 1).

In the same period, additional TB samples from NPC patients were collected from NPC endemic regions in Asia, including 122 samples from SYSUCC, 30 samples 
Table 1 Characteristics of samples from nasopharyngeal carcinoma (NPC) cases and healthy controls from the four casecontrol datasets

\begin{tabular}{|c|c|c|c|c|c|c|c|}
\hline \multirow[t]{2}{*}{ Dataset } & \multirow[t]{2}{*}{ Region } & \multirow[t]{2}{*}{ Period } & \multicolumn{2}{|l|}{ NPC cases } & \multicolumn{2}{|l|}{ Healthy controls } & \multirow[t]{2}{*}{ Note } \\
\hline & & & $\begin{array}{l}\text { Detected/ } \\
\text { total (no.) }\end{array}$ & Source & $\begin{array}{l}\text { Detected/total } \\
\text { (no.) }\end{array}$ & Source & \\
\hline Data_GD1 & Guangdong & Oct 2005-Oct 2007 & $157 / 346$ & $\begin{array}{l}\text { Sun Yat-sen Univer- } \\
\text { sity Cancer Center } \\
\text { (SYSUCC) }\end{array}$ & $319 / 448$ & $\begin{array}{l}\text { The First Affiliated } \\
\text { Hospital of Sun } \\
\text { Yat-sen University } \\
\text { (1st AH-SYSU) }\end{array}$ & NPC endemic \\
\hline Data_GD2 & Guangdong & Oct 2008-Jun 2013 & $168 / 222$ & SYSUCC & $241 / 315$ & 1st AH-SYSU & NPC endemic \\
\hline Data_GD3 & Guangdong & Oct 2008-Jun 2013 & $726 / 1065$ & $\begin{array}{l}\text { Local hospitals } \\
\text { in Guangdong } \\
\text { province }\end{array}$ & $880 / 1161$ & $\begin{array}{l}\text { Local hospitals } \\
\text { in Guangdong } \\
\text { province }\end{array}$ & NPC endemic \\
\hline Data_SD & Shandong & Oct 2008-Jun 2013 & $58 / 102$ & $\begin{array}{l}\text { The Affiliated Hos- } \\
\text { pital of Qingdao } \\
\text { University, the } \\
\text { Shandong Province } \\
\text { Cancer Center }\end{array}$ & $612 / 1543$ & $\begin{array}{l}\text { Local hospitals } \\
\text { in Shandong } \\
\text { province }\end{array}$ & NPC non-endemic \\
\hline
\end{tabular}

from the National Cancer Center of Singapore in Singapore, and 30 samples from the Chinese University of Hong Kong in Hong Kong. TB samples from patients with EBV-related malignancies were also collected, including 10 samples of gastric carcinoma from AH-QDU and 23 samples of lymphoma (Burkitt's, NK/T cell, or Hodgkin's) from SYSUCC. An additional $39 \mathrm{TW}$ samples from patients with non-EBV-associated cancers were collected at SYSUCC. TW samples were also collected from healthy subjects in NPC non-endemic regions, including 83 samples from the Medical Examination Center of Henan Provincial Military Department in Henan Province, 100 samples from the Beijing Centers for Diseases Control and Prevention in Beijing, 116 samples from the Third People's Hospital of Datong in Shanxi Province, and 11 Caucasian samples from the Karolinska Institute in Sweden and the VU University Medical Center in Netherlands.

The selection criteria for patients were self-reported Chinese and newly diagnosed patients without any radiotherapy, chemotherapy, or surgery. TW samples were collected before any treatment. Basic information was also collected from the participants regarding age, gender, residential region, ethnicity, and familial history of NPC or other cancers. Healthy controls with no self-reported history of cancer were randomly recruited from physical examination centers in hospitals and were frequencymatched to the cases by age ( \pm 5 years), gender, residential region, and ethnicity. This study was approved by the Human Ethics Committee at SYSUCC. Written informed consent was obtained from all the participants.

\section{Isolation of DNA}

Genomic DNA from TW samples was prepared using a conventional method. Briefly, the subjects rinsed their mouths with $15 \mathrm{~mL}$ of $0.9 \%$ saline for $10 \mathrm{~s}$. Buccal epithelial cells were pelleted by centrifugation at $5000 \times g$ for $10 \mathrm{~min}$. The cells were re-suspended and digested in a lysis buffer $[10 \mathrm{mmol} / \mathrm{L}$ Tris. $\mathrm{HCl}$ with $\mathrm{pH}$ 8.0, $100 \mathrm{mmol} / \mathrm{L} \mathrm{NaCl}, 25 \mathrm{mmol} / \mathrm{L}$ ethylene diamine tetraacetic acid (EDTA), 0.5\% Sarkosyl, and $0.1 \mathrm{mg} / \mathrm{mL}$ proteinase $\mathrm{K}]$ for $1-2 \mathrm{~h}$ at $55{ }^{\circ} \mathrm{C}$. After treatment with RNase A, DNA was extracted from the cell lysate by adding phenol/chloroform and then precipitated with ethanol, followed by dissolving in $50 \mu \mathrm{L}$ of water. Genomic DNA from TB samples and cells was extracted using a commercial DNA extraction kit (DNeasy Blood \& Tissue Kit, Qiagen, Valencia, CA, USA).

\section{Sequence analysis and detection of SNP in RPMS1}

In the pilot study, sequences of $L M P 1, E B N A 1$, and the $B A R T s$ family were detected by standard PCR and the direct Sanger sequencing method [22]. For RPMS1, only the second coding exon was considered (sequence length approximately $282 \mathrm{bp}$, covering $89.74 \%$ of the RPMS1 coding region), as there was no variation in the first exon according to pairwise comparisons among GD1, AG876, and two wild-type EBV genomes (GenBank Accession No. AY961628, DQ279927, AJ507799, and NC_007605). Considering the low number of DNA copies of EBV in the TW samples, three rounds of nested PCR were subsequently conducted to amplify the RPMS1 fragment as a way to increase the detection rate. Three primer pairs are listed in Table 2. In the first round, $2 \mu \mathrm{L}$ of each genomic DNA served as the template, and PCR was performed in a $25-\mu \mathrm{L}$ reaction system containing $0.25 \mu \mathrm{L}$ of $20 \mu \mathrm{mol} / \mathrm{L}$ primer pair RPMS1-1/2, $2.0 \mathrm{mmol} / \mathrm{L}$ magnesium chloride, $0.2 \mathrm{mmol} / \mathrm{L}$ of each dNTP, and 0.625 unit of Go Taq DNA polymerase (Promega, Madison, WI, USA). In the 
Table 2 Primers used in the nested polymerase chain reaction (PCR) and their sequences

\begin{tabular}{|c|c|c|c|}
\hline Primer & EBV locus $^{\mathrm{a}}$ & Sequences $\left(5^{\prime} \rightarrow 3^{\prime}\right)$ & Note \\
\hline EBNA1-1 & $96,750-67$ & GGGAAGTCGTGAAAGAGC & Outer primer \\
\hline EBNA1-2 & $97,479-96$ & GGTGGAAACCAGGGAGGC & \\
\hline EBNA1-3 & $97,052-72$ & $\begin{array}{l}\text { GGTTTGGAAAGCATCGT } \\
\text { GGTC }\end{array}$ & Inner primer \\
\hline EBNA1-4 & $97,390-410$ & $\begin{array}{l}\text { AACAAGGTCCTTAATC } \\
\text { GCATC }\end{array}$ & \\
\hline LMP1-CT-1 & $167,623-42$ & $\begin{array}{l}\text { GCTAAGGCATTCCCA } \\
\text { GTAAA }\end{array}$ & Outer primer \\
\hline LMP1-CT-2 & $168,268-86$ & GATGAACACCACCACGATG & \\
\hline LMP1-CT-3 & $167,755-72$ & CGGAACCAGAAGAACCCA & Inner primer \\
\hline LMP1-CT-4 & $168,244-61$ & TCCCGCACCCTCAACAAG & \\
\hline RPMS1-1 & $155,087-107$ & $\begin{array}{l}\text { GCTGGGTTGATGCTGT } \\
\text { AGATG }\end{array}$ & 1 st round nested \\
\hline RPMS1-2 & $155,799-819$ & $\begin{array}{l}\text { AGGGTCTGGACGTGGA } \\
\text { GTTTG }\end{array}$ & \\
\hline RPMS1-3 & $155,103-121$ & AGATGTGCCTGGCTCTGTC & 2nd round nested \\
\hline RPMS1-4 & $155,543-63$ & $\begin{array}{l}\text { CAATGACTTTGTCACCT } \\
\text { TTGG }\end{array}$ & \\
\hline RPMS1-5 & $155,199-220$ & $\begin{array}{l}\text { AGAAGGCGTAGAGCATG } \\
\text { TCCAG }\end{array}$ & 3rd round nested \\
\hline RPMS1-6 & $155,460-81$ & $\begin{array}{l}\text { GAGTACGACTGTGAGG } \\
\text { TGGGCG }\end{array}$ & \\
\hline
\end{tabular}

EBV Epstein-Barr virus, EBNA1 EBV nuclear antigen 1, LMP1 latent membrane protein 1

a Coordinates relative to complete wild-type EBV genome (GenBank Accession No. NC_007605)

second round, $2 \mu \mathrm{L}$ of mixture from the first round PCR was used as the template with the primer pair RPMS1-3/4 in a $25-\mu \mathrm{L}$ reaction system. In the third round, the template was $5 \mu \mathrm{L}$ of mixture from the second round PCR, using the primer pair RPMS1-5/6, in a $50-\mu \mathrm{L}$ reaction system. Raji DNA and water were used as positive and negative controls, respectively. The amplification procedures for each round followed the manufacturer's protocol. After PCR amplification, the nucleotide sequences of the PCR products were determined by Sanger sequencing (Fig. 1).

\section{Cell culture}

NP69 is an immortalized human nasopharyngeal epithelial cell line originally presented by George Tsao at the University of Hong Kong and maintained at SYSUCC. NP69 cells were grown in defined Keratinocyte serumfree medium supplemented with epidermal growth factor (EGF) (Invitrogen, Grand Island, NY, USA). The purity of NP69 cells was verified using short tandem repeat (STR) markers with the Goldeneye ${ }^{\mathrm{TM}} 20 \mathrm{~A}$ STR kit (Peoplespot Co., Beijing, China) and an ABI 3100 analyzer (Thermo Fisher Scientific, Grand Island, NY, USA). Raji and C666-1 cells were maintained at our laboratory and cultured in RPMI-1640 medium supplemented with $10 \%$ fetal bovine serum (Gibco, Grand Island, NY, USA). 293T cells were maintained at our laboratory and grown in Dulbecco's modified eagle medium supplemented with $10 \%$ fetal bovine serum (Gibco). All cells were cultured in a humidified chamber with $5 \% \mathrm{CO}_{2}$ at $37^{\circ} \mathrm{C}$.

\section{Plasmids and generation of stable RPMS1 expression transfectants}

Full-length cDNA of RPMS1 was obtained by PCR from the cDNA library derived from the EBV-positive NPC cell line C666-1 and then cloned into the pBABE-Puro retroviral vector (Cell Biolabs, San Diego, CA, USA). Mutations were introduced using the Quick-Change SiteDirected Mutagenesis Kit (Stratagene, Santa Clara, CA, USA), and all mutations were verified by Sanger sequencing. The pBABE-Puro-RPMS1 (-Mut/-WT) expression vectors (constructed at our laboratory) and their corresponding control vectors (Cell Biolabs) were packaged into the retrovirus generated by $293 \mathrm{~T}$ cells, followed by the infection of NP69 cells. The respective stable transfectants in NP69 cells were selected against $1 \mu \mathrm{g} / \mathrm{mL}$ of puromycin.

\section{Western blotting}

Western blotting was performed as described previously [30]. Briefly, cells were lysed in mammalian cell lysis buffer, and proteins within the clarified lysates were resolved by sodium dodecyl sulfate-polyacrylamide gel electrophoresis (SDS-PAGE) and transferred to polyvinylidene difluoride (PVDF) membranes for immunoblotting against the corresponding antibody. The results were revealed using enhanced chemiluminescent (ECL) detection reagents (Beyotime Co., Shanghai, China). The rabbit polyclonal anti-RPMS1 antibody was from Proteintech Group Inc. (Wuhan, Hubei, China), and the human anti$\beta$-actin antibody was from Sigma-Aldrich Co. (St. Louis, MO, USA). A horseradish peroxidase (HRP)-conjugated anti-rabbit IgG antibody was used as the secondary antibody (Promega, Madison, WI, USA).

\section{Statistical analysis}

To test the association between EBV variations and NPC risk, odds ratios (ORs) and 95\% confidence intervals (CIs) were estimated by unconditional logistic regression. Subjects with the EBV prototype (155391G) were treated as the reference. ORs were adjusted for gender and age, where both were taken as categorical covariates (female or male; $\leq 35,35-65$, and $>65$ years). Fisher's exact test was used to assess the frequency distribution of variables in two or more groups. The NPC risk associated with the affected EBV variations was characterized using the Cochran-Armitage trend test in the logistic 


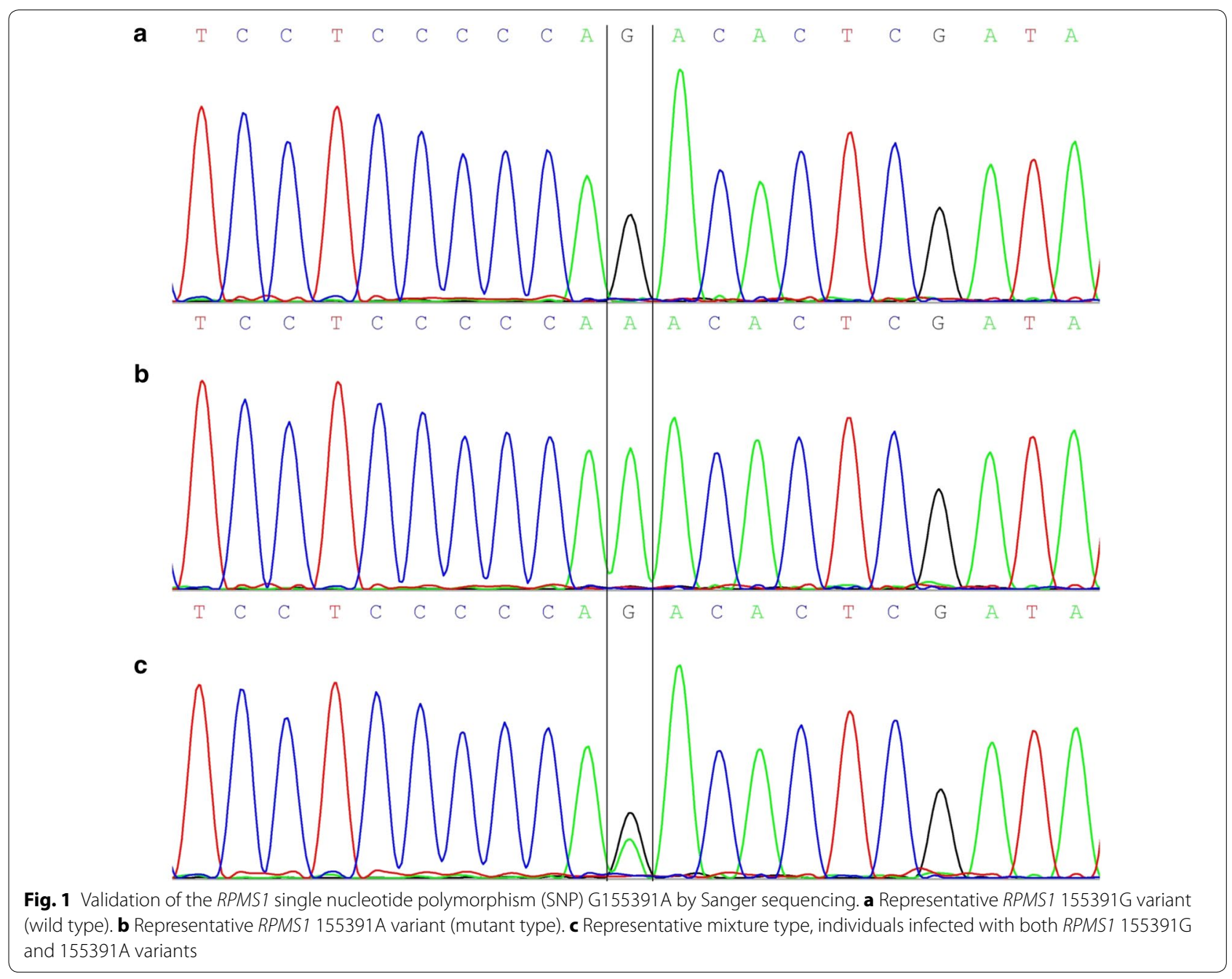

regression analysis with adjustment for gender and age, where the variables of the EBV variations 155391G, $155391 \mathrm{G} / \mathrm{A}$, and $155391 \mathrm{~A}$ were coded by 0,1 , and 2 in the statistical model, respectively. All statistical analyses were performed using the R3.0.1 software (http://www.rproject.org/). A $P$ value of less than 0.05 was considered significant.

\section{Results}

\section{Association between a SNP in the EBV genome and high} risk of NPC

To identify genomic variations related to the NPC disease phenotype, in the pilot study, we sequenced the genomic regions of EBV-encoded genes, including $L M P 1, E B N A 1$, and the BARTs family, in 60 paired TW samples from NPC patients and healthy controls from a Cantonese population. Because, in NPC patients, multiple subtypes of EBV infection could be detected frequently in peripheral blood samples, and the EBV subtype detected in the normal nasopharyngeal tissues was more similar to the subtype in the TB samples $[16,22]$, we chose to sequence DNA extracted from the TW samples. We found one SNP in RPMS1 (Loc155391 $\mathrm{G}>\mathrm{A}$ ) with a significant difference between the cases and controls, and all the subsequent experiments on larger sample sizes were then focused on this genomic variation. In contrast, no significant associations with NPC risk were observed at the EBNA1 and LMP1 loci (Table 3).

In the discovery stage, TW samples from 157 NPC patients and 319 controls recruited from Guangdong Province were genotyped based on the 2nd exon sequence of RPMS1 (Data_GD1; Table 1). The SNP was recognized as Loc155391 (G>A) based on its coordinates mapping to the wild-type EBV genome (GenBank Accession No. NC_007605). Logistic regression analysis with adjustment for age and gender revealed a strong association of the SNP at Loc155391 (named as G155391A) with 
Table 3 Association between variations of EBNA1 and LMP1 in throat washing (TW) samples and the risk of NPC in Guangdong population (pilot study)

\begin{tabular}{llccc}
\hline Gene & Subtype & $\begin{array}{l}\text { NPC } \\
\text { [no. (\%)] }\end{array}$ & $\begin{array}{l}\text { Healthy subjects } \\
\text { [no. (\%)] }\end{array}$ & $P$ \\
\hline RPMS1 & & & & $<0.001$ \\
& 155391G & $8(16.0)$ & $29(53.7)$ & \\
& 155391G/A & 0 & $4(7.4)$ & 0.677 \\
& 155391A & $42(84.0)$ & $21(38.9)$ & \\
EBNA1 & & & & \\
& V-val & $45(90.0)$ & $44(84.6)$ & 0.080 \\
& P-ala & $1(2.0)$ & $2(3.8)$ & \\
& P-thr & $2(4.0)$ & $1(1.9)$ & \\
& Mix & $2(4.0)$ & $5(9.6)$ & \\
LMP1 & & & & \\
& China 1 & $27(64.3)$ & $39(68.4)$ & \\
& China 2 & $4(9.5)$ & $2(3.5)$ & \\
& B95.8 & $2(4.8)$ & $10(17.5)$ & \\
& Mix & $9(21.4)$ & $6(10.5)$ & \\
\hline
\end{tabular}

Mix mixture of two or more EBV subtypes. Other abbreviations as in Tables 1 and 2

a high risk of NPC $(P<0.001, \mathrm{OR}=4.47,95 \%$ CI $2.71-$ 7.37; Table 4).

\section{Replication analyses}

To replicate the association, Loc155391 was genotyped in two independent sample groups recruited from the same NPC endemic region, consisting of 168 NPC patients and 241 healthy controls from Data_GD2 and 726 NPC patients and 880 healthy controls from Data GD3 (Table 1). Logistic regression analysis showed that SNP G155391A was significantly associated with a high NPC risk in both sample groups (Data_GD2: $P<0.001$, $\mathrm{OR}=5.20,95 \%$ CI 3.18-8.50; Data_GD3: $P<0.001$, $\mathrm{OR}=5.27,95 \%$ CI 4.06-6.85; Table 4), indicating that the strong association was replicated in the two independent sample groups. As further confirmation, logistic regression analysis for SNP G155391A was conducted in another sample group from Shandong Province in North China, which is a NPC non-endemic region, involving 58 NPC patients and 612 healthy controls (Data_SD). The result revealed a consistently strong association between SNP G155391A and a high NPC risk $(P<0.001$, $\mathrm{OR}=7.52$, 95\% CI 3.69-15.32; Table 4), indicating that the association was further replicated. Meta-analysis of all the four samples with a total of 1109 NPC patients and 2052 healthy controls showed that SNP G155391A was associated with a high risk of NPC among all tested regions $(P<0.001, \mathrm{OR}=5.27,95 \% \mathrm{CI} 4.31-6.44)$, and there was no evidence of heterogeneity among the
Table 4 Single nucleotide polymorphism (SNP) G155391A of RPMS1 and NPC risk

\begin{tabular}{|c|c|c|c|c|c|}
\hline EBV variant & NPC & Healthy subjects & OR & $95 \% \mathrm{Cl}$ & $P$ value \\
\hline \multicolumn{6}{|l|}{ Data_GD1 } \\
\hline $155391 \mathrm{G}$ & 28 & 132 & 1 & & \\
\hline G155391A & 10 & 40 & 1.53 & $0.66-3.54$ & 0.321 \\
\hline $155391 \mathrm{~A}$ & 119 & 147 & 4.47 & $2.71-7.37$ & $<0.001$ \\
\hline$P_{\text {trend }}^{\dagger}$ & & & & & $<0.001$ \\
\hline \multicolumn{6}{|l|}{ Data_GD2 } \\
\hline $155391 \mathrm{G}$ & 28 & 125 & 1 & & \\
\hline G155391A & 2 & 5 & 1.98 & $0.35-11.33$ & 0.443 \\
\hline 155391A & 138 & 111 & 5.20 & $3.18-8.50$ & $<0.001$ \\
\hline$P_{\text {trend }}^{\dagger}$ & & & & & $<0.001$ \\
\hline \multicolumn{6}{|l|}{ Data_GD3 } \\
\hline $155391 \mathrm{G}$ & 99 & 357 & 1 & & \\
\hline G155391A & 12 & 84 & 0.61 & $0.32-1.17$ & 0.136 \\
\hline 155391A & 615 & 439 & 5.27 & $4.06-6.85$ & $<0.001$ \\
\hline$P_{\text {trend }}^{\dagger}$ & & & & & $<0.001$ \\
\hline \multicolumn{6}{|l|}{ Data_SD } \\
\hline $155391 \mathrm{G}$ & 40 & 560 & 1 & & \\
\hline G155391A & 0 & 18 & 0 & $0-\operatorname{Inf}$ & 0.987 \\
\hline 155391A & 18 & 34 & 7.52 & $3.69-15.32$ & $<0.001$ \\
\hline$P_{\text {trend }}^{\dagger}$ & & & & & $<0.001$ \\
\hline \multicolumn{6}{|l|}{ Overall } \\
\hline $155391 \mathrm{G}$ & 195 & 1174 & 1 & & \\
\hline G155391A & 24 & 147 & 0.92 & $0.56-1.51$ & 0.746 \\
\hline $155391 \mathrm{~A}$ & 890 & 731 & 5.27 & $4.31-6.44$ & $<0.001$ \\
\hline$P_{\text {trend }}^{\dagger}$ & & & & & $<0.001$ \\
\hline$R^{2}$ & & & 0 & & \\
\hline$p^{\ddagger}$ & & & & & 0.710 \\
\hline
\end{tabular}

OR odds ratio, $95 \% \mathrm{Cl} 95 \%$ confidence interval, Inf Infinity. Other abbreviations as in Tables 1 and 2

${ }^{a}$ Datasets integrated by meta-analysis

${ }^{\dagger} P_{\text {trend }}$ Cochran-Armitage trend test in logistic regression analysis with adjustment for age and gender

₹ $P$ heterogeneity test among the four datasets

included cohorts $(P=0.71$; Table 4$)$. In addition, no other variations of RPMS1 were observed in any of the four sample groups.

\section{Association of RPMS1 SNP G155391A and incidences of NPC and other malignancies}

The frequencies of SNP G155391A were counted and compared among samples from Guangdong in South China, which is an NPC endemic region, as well as in North China and Europe, where NPC incidence is relatively low. High frequencies of SNP G155391A were detected among the controls from Guangdong (48.4\%), whereas the frequencies were significantly lower in North China $(1.2 \%-8.0 \%)$ and Europe $(0)(P<0.001$; Table 5$)$. 
Table 5 The frequencies of RPMS1 SNP G155391A in NPC cases and healthy controls from various world regions

\begin{tabular}{|c|c|c|c|c|c|c|c|c|c|}
\hline \multirow[t]{2}{*}{ Sample } & \multirow[t]{2}{*}{ Source } & \multirow[t]{2}{*}{ Region } & \multirow[t]{2}{*}{ No. (sum) } & \multicolumn{3}{|c|}{ G155391A } & \multirow{2}{*}{$\begin{array}{l}\text { Frequency } \\
\text { of G155391A (\%) }\end{array}$} & \multirow[t]{2}{*}{ NPC incidence } & \multirow[t]{2}{*}{$P^{*}$} \\
\hline & & & & G & $G / A$ & A & & & \\
\hline \multirow[t]{6}{*}{ NPC } & $\mathrm{TB}$ & Shandong & 36 & 23 & 0 & 13 & 36.1 & Low & \\
\hline & & Guangdong & 122 & 22 & 0 & 100 & 82.0 & High & \\
\hline & & Hong Kong & 30 & 2 & 0 & 28 & 93.3 & High & \\
\hline & & Singapore & 30 & 9 & 0 & 21 & 70.0 & High & $<0.001$ \\
\hline & TW & Shandong & 22 & 17 & 0 & 5 & 22.7 & Low & \\
\hline & & Guangdong & 1051 & 155 & 24 & 872 & 83.0 & High & $<0.001$ \\
\hline \multirow[t]{6}{*}{ Healthy subjects } & TW & Europe & 11 & 11 & 0 & 0 & 0.0 & Low & \\
\hline & & Henan & 83 & 81 & 1 & 1 & 1.2 & Low & \\
\hline & & Beijing & 100 & 91 & 1 & 8 & 8.0 & Low & \\
\hline & & Shanxi & 116 & 109 & 1 & 6 & 5.2 & Low & \\
\hline & & Shandong & 612 & 560 & 18 & 34 & 5.6 & Low & \\
\hline & & Guangdong & 1440 & 614 & 129 & 697 & 48.4 & High & $<0.001$ \\
\hline
\end{tabular}

TB tumor biopsy. Other abbreviations as in Tables 1 and 2

* Data combined in regions with low/high NPC incidence and probability calculated by Fisher's exact test

The increasing trend in the frequency of SNP G155391A in samples from regions with low to high NPC incidence was consistently observed in NPC patients, using either TW or TB samples (both $P<0.001$; Table 5). These results indicated that the frequency of SNP G155391A was associated with the NPC incidence and was significantly increased in the tumor tissues. Moreover, as Burkitt's lymphoma, Hodgkin's lymphoma, NK/T-cell lymphoma, and some gastric cancers are well known as EBV-related malignancies, we compared the distributions of the RPMS1 SNP G155391A between other cancer samples and healthy controls. Interestingly, no evidence of association was observed between the RPMS1 SNP G155391A and the risks of tested cancers except for NPC $(P>0.05$; Table 6$)$, suggesting that the association with the high-risk EBV variant might be specific to NPC.

\section{Functional characterization of RPMS1 SNP G155391A}

Endogenous RPMS1 protein was not detected, even though RPMS1 was implicated in NPC development. Although the BARTs contain many EBV-encoded microRNA precursors [31], we failed to detect any alteration in the microRNAs predicted in the regions near RPMS1 between the wild-type (155391G) and mutant (155391A) RPMS1 (data not shown). Thus, we suspected that the variation of G155391A from guanine $(G)$ to adenine (A), leading to the amino acid change from Asp (D) to Asn $(\mathrm{N})$, might be related to RPMS1 transcription or expression. Variations of the stable nasopharyngeal epithelial cell line NP69 integrating pBABE-Puro retroviral vector with mutant RPMS1 (155391A), wild-type RPMS1 (155391G), and empty vector, respectively, were successfully constructed as revealed by Western blotting (Fig. 2a).
After cycloheximide (CHX) treatment, RPMS1 protein degradation was clearly proceeding after $0.5 \mathrm{~h}$ in the NP69 cells with wild-type RPMS1 (155391G), whereas the degradation was hampered in the NP69 cells with mutant RPMS1 (155391A) (Fig. 2b). Moreover, the damped exponential model indicated that the half-life for the mutant RPMS1 protein was significantly longer than that for the wild-type protein ( 3.2 vs. $0.6 \mathrm{~h}, P<0.001$; Fig. 2 c), suggesting that the SNP G155391A is functionally regulating the protein stability of RPMS1. In addition, when treated with the proteasome inhibitor MG132, a significant increase in RPMS1 protein expression was observed in the stable NP69 cell lines with overexpression of either wildtype (155391G) or mutant RPMS1 (155391A) (Fig. 2d), suggesting that the RPMS1 protein might be degraded through the ubiquitin-proteasome pathway.

\section{Discussion}

In this multi-stage association study with a large sample size, we identified an EBV genomic sequence variation represented by RPMS1 SNP G155391A that was associated with a high risk of NPC. This association is much stronger than those of non-viral environmental factors, such as the consumption of salted fish and preserved food, with NPC risk [32-34]. The frequency of RPMS1 SNP G155391A was significantly associated with the NPC incidence, and higher frequencies were observed in the NPC endemic areas, suggesting that RPMS1 SNP G155391A might explain the different incidences of NPC worldwide. RPMS1 SNP G155391A was enriched in NPC patients but was not associated with other malignancies; these results support the hypothesis that there is a highly oncogenic EBV subtype specifically leading to NPC risk. 
Table 6 Association of RPMS1 SNP G155391A with the risk of NPC and other malignancies

\begin{tabular}{|c|c|c|c|c|c|c|}
\hline Region & Sample & Source & 155 & A $155391 \mathrm{~A}$ & OR & $P$ \\
\hline \multirow[t]{6}{*}{ Guangdong } & Healthy subjects $^{a}$ & TW & 743 & 697 & 1 & \\
\hline & EBV-free tumor ${ }^{\#}$ & TW & 24 & 15 & $0.67^{\dagger}$ & 0.257 \\
\hline & $\mathrm{NHL}^{\neq}$ & $\mathrm{TB}$ & 8 & 5 & $0.67^{\dagger}$ & 0.582 \\
\hline & $\mathrm{HL}$ & TB & 7 & 3 & $0.46^{+}$ & 0.345 \\
\hline & Lymphoma (NHL + HL) & TB & 15 & 8 & $0.57^{\dagger}$ & 0.213 \\
\hline & NPC & $\mathrm{TB}$ & 22 & 100 & $8.35^{\wedge}$ & $<0.001$ \\
\hline \multirow[t]{3}{*}{ Shandong } & Healthy subjects $^{a}$ & TW & 578 & 34 & 1 & \\
\hline & EBVaGC & TB & 10 & 0 & $0^{+}$ & 1.000 \\
\hline & NPC & $\mathrm{TB}$ & 23 & 13 & $\operatorname{lnf} f^{2}$ & 0.042 \\
\hline
\end{tabular}

NHL non-Hodgkin's lymphoma, HL Hodgkin's lymphoma, EBVaGC EBV-associated gastric carcinoma. Other abbreviations as in Tables 1 and 2

a Healthy subjects from the discovery and replication stages were combined

\# EBV-free tumors included lung cancer, liver cancer, colorectal cancer, and pancreatic cancer, among others, which were not associated with EBV

* NHL included Burkitt's and NK/T-cell lymphomas

† The frequency of RPMS1 SNP G155391A in healthy subjects from the same region was considered as a reference, with Fisher's exact test performed

Lymphoma was considered as a reference

EBVaGC was considered as a reference

a

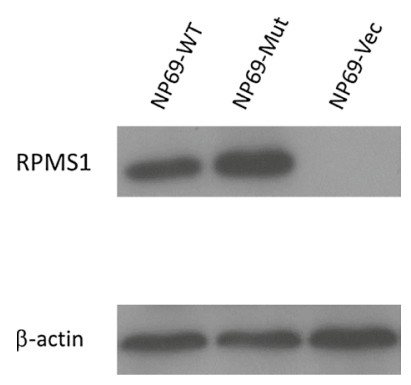

C

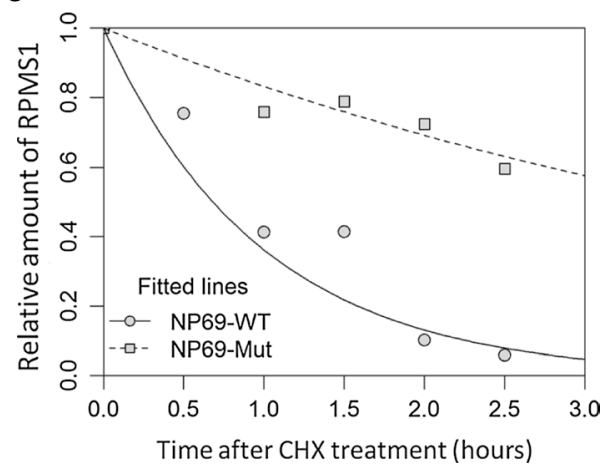

b

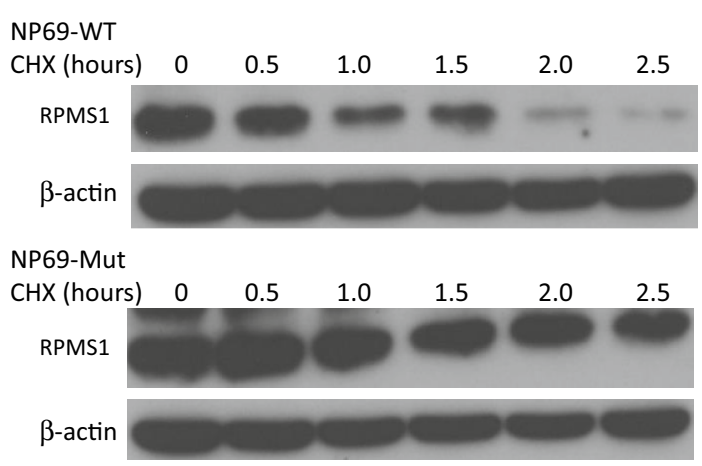

d

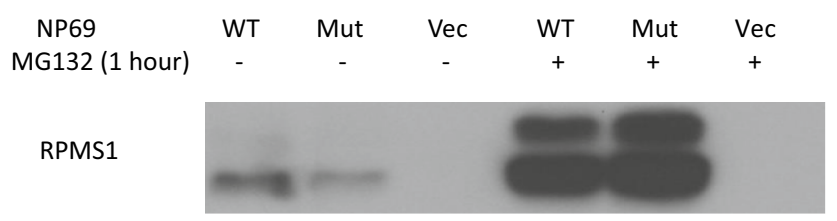

$\beta$-actin

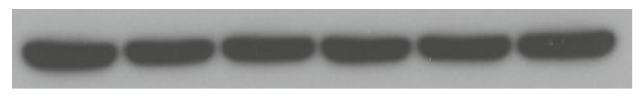

Fig. 2 Effect of the RPMS1 SNP G155391A on the degradation of RPMS1 protein. a Western blotting analysis showing the expression levels of RPMS1 in NP69 cell lines established with the stable integration of the pBABE-Puro retroviral vector of mutant RPMS1 (-Mut), wild-type RPMS1 (-WT), and control vector $(-\mathrm{Vec})$, respectively. b Western blotting results showing the degradation of RPMS1 protein. NP69 cells with stable overexpression of mutant RPMS1 (-Mut) or wild-type RPMS1 (-WT) were incubated with $20 \mu \mathrm{g} / \mathrm{mL}$ cycloheximide (CHX) for the indicated periods of time $(0,0.5$, $1.0,1.5,2.0$, and 2.5 h). $\mathbf{c}$ Fitted curves of the degradation of the RPMS1 protein of EBV variations under the damped exponential model. $\mathbf{d}$ Western blotting results showing the RPMS1 protein expression in NP69 cells with stable overexpression of mutant RPMS1 (-Mut) or wild-type RPMS1 (-WT), treated with or without $10 \mu \mathrm{mol} / \mathrm{L}$ MG132 for $1 \mathrm{~h}$ 
The identification of the high-risk RPMS1 SNP G155391A for NPC emphasizes that the contribution of EBV strain variation to virus-associated malignancies should not be ignored. A similar scenario is the association of human papillomavirus (HPV) with cervical carcinomas, in which highly oncogenic HPV subtypes 16,18 , and 45 are the predominant contributors to the disease among more than 150 HPV subtypes [35, 36]. Therefore, HPV vaccine programs have shown promising population-level impacts, and the screening of HPV subtypes is important for the early detection of cervical carcinomas [37]. Indeed, serological EBV markers are potentially useful for screening individuals with a high risk of NPC in multiplex families [38]. The identification of the high-risk RPMS1 SNP G155391A suggests that we should consider the contribution of EBV variations to the applications of serological EBV markers, such as DNA in NPC monitoring and prognostication [39]. With further investigation of other high-risk EBV variations, if any, we might be able to develop effective vaccines against high-risk EBV subtypes to promote NPC prevention.

RPMS1 is a unique gene belonging to the EBV BARTs family, which is abnormally expressed in most NPC tissues at the RNA level and might contribute to NPC development [25, 26]. No endogenous RPMS1 protein has been reported in cultured NPC cells or NPC tumor biopsies [40], and thus, we suspected that RPMS1 might be translated into protein at very low levels, or else that the RPMS1 protein was degraded very rapidly. Indeed, we found that the RPMS1 variations defined by $155391 \mathrm{~A}$ and $155391 \mathrm{G}$ are functionally relevant to the stability of RPMS1 protein overexpressed in vitro (Fig. 2). Compared with the low-risk 155391G, the high-risk 155391A resulted in a longer half-life of RPMS1 protein, as shown in the protein degradation assays. With oncogenic capacity, RPMS1 has been shown to interact with the Notch intracellular domain and regulate the downstream pathway to promote cell differentiation and proliferation [41]. A recent genome sequencing study of NPC revealed accumulated mutations in the genes involved in the Notch pathway, including $\mathrm{NOTCH1}, \mathrm{NOTCH} 2$, and NOTCH3 [42], suggesting that the dysregulation of the Notch pathway might be an important driving event in NPC. These results further suggest that the interaction between EBVencoded RPMS1 and the host Notch pathway might be a significant process during NPC development and that the high-risk 155391A, leading to a longer half-life of RPMS1 protein, may exhibit stronger carcinogenesis potential.

\section{Conclusions}

We discovered a high-risk EBV SNP for NPC, which suggests the existence of disease-related EBV subtypes. Moreover, our findings indicate that different distributions of EBV subtypes in different geographic regions and ethnic groups might be among the reasons for the differences in NPC incidence worldwide. Therefore, our results provide new insights for screening populations at a high risk of NPC and strategies for $\mathrm{EBV}$ vaccine development in the future. We acknowledge that further studies with larger sample sizes, more ethnic groups, and more geographic regions are needed to replicate our findings and rule out the confounding effects of population and the source of EBV, as the RPMS1 SNP G155391A had much higher frequency in the Guangdong area based on TW samples. Certainly, more efforts are required to analyze the whole genome sequence of EBV to define haplotypes, instead of a single SNP, for genotyping the virus detected in healthy subjects or patients with different disorders and different ethnicities.

\section{Authors' contributions}

YXZ and JXB conceived the study and supervised the work. YMG, QSF, LZC, MX, BL, DJL, LFH, JMM, OR, QT, and SMC prepared the samples. FTF and QC performed the experiments. WHJ reviewed the cases. FTF, QC, and WSL performed the analyses. FTF, QC, JXB, and YXZ interpreted the results and wrote the manuscript. All authors read and approved the final manuscript.

\section{Author details \\ 1 Sun Yat-sen University Cancer Center, State Key Laboratory of Oncology in South China, Collaborative Innovation Center for Cancer Medicine, Guang- zhou 510060, Guangdong, P. R. China. ${ }^{2}$ Department of Experimental Research, Sun Yat-sen University Cancer Center, Guangzhou 510060, Guangdong, P. R. China. ${ }^{3}$ Department of Medical Microbiology, Qingdao University Medical College, Qingdao 266021, Shandong, P. R. China. ${ }^{4}$ Department of Microbiol- ogy, Tumor and Cell Biology, Karolinska Institute, 17177 Stockholm, Sweden. ${ }^{5}$ Department of Pathology, VU University Medical Center, Amsterdam 1007 MB, The Netherlands. ${ }^{6}$ Department of Clinical Oncology, The Chinese Univer- sity of Hong Kong, Hong Kong 999077, P. R. China. ${ }^{7}$ Department of Epide- miology, Cancer Prevention Center, Sun Yat-sen University Cancer Center, Guangzhou 510060, Guangdong, P. R. China.}

\section{Acknowledgements}

This work was supported by the National Basic Research Program of China (973 Plan, No. 2011 CB504301 and No. 2011CB504302), the High-Tech Research and Development Program of China (863 Plan, No. 2012AA02A206 and No. 2012AA02A501), the Program for New Century Excellent Talents at Sun Yat-sen University (No. NCET-11-0529), and the Specialized Research Fund for the Doctoral Program of Higher Education (No. 20110171120099).

We thank all the recruited participants in this work and all the staff members that participated in the sample collections from the listed institutions.

\section{Competing interests}

The authors declare that they have no competing interests.

Received: 25 July 2015 Accepted: 18 November 2015

Published online: 16 December 2015

\section{References}

1. McDermott AL, Dutt SN, Watkinson JC. The aetiology of nasopharyngeal carcinoma. Clin Otolaryngol Allied Sci. 2001;26(2):82-92.

2. Bei JX, Li Y, Jia WH, Feng BJ, Zhou G, Chen LZ, et al. A genome-wide association study of nasopharyngeal carcinoma identifies three new susceptibility loci. Nat Genet. 2010;42(7):599-603. doi:10.1038/ng.601.

3. Wei WI, Sham JS. Nasopharyngeal carcinoma. Lancet. 2005;365(9476):2041-54. doi:10.1016/S0140-6736(05)66698-6. 
4. Young LS, Rickinson AB. Epstein-Barr virus: 40 years on. Nat Rev Cancer. 2004;4(10):757-68. doi:10.1038/nrc1452.

5. Raab-Traub N, Flynn K, Pearson G, Huang A, Levine P, Lanier A, et al. The differentiated form of nasopharyngeal carcinoma contains Epstein-Barr virus DNA. Int J Cancer. 1987;39(1):25-9.

6. Chien YC, Chen JY, Liu MY, Yang HI, Hsu MM, Chen CJ, et al. Serologic markers of Epstein-Barr virus infection and nasopharyngeal carcinoma in Taiwanese men. N Engl J Med. 2001;345(26):1877-82. doi:10.1056/ NEJMoa011610.

7. Lin JC, Wang WY, Chen KY, Wei YH, Liang WM, Jan JS, et al. Quantification of plasma Epstein-Barr virus DNA in patients with advanced nasopharyngeal carcinoma. N Engl J Med. 2004;350(24):2461-70. doi:10.1056/ NEJMoa032260.

8. Houldcroft CJ, Kellam P. Host genetics of Epstein-Barr virus infection, latency and disease. Rev Med Virol. 2015;25(2):71-84. doi:10.1002/ rmv.1816.

9. Chang CM, Yu KJ, Mbulaiteye SM, Hildesheim A, Bhatia K. The extent of genetic diversity of Epstein-Barr virus and its geographic and disease patterns: a need for reappraisal. Virus Res. 2009;143(2):209-21. doi:10.1016/j. virusres.2009.07.005

10. Young LS, Dawson CW. Epstein-Barr virus and nasopharyngeal carcinoma. Chin J Cancer. 2014;33(12):581-90. doi:10.5732/cjc.014.10197.

11. Palser AL, Grayson NE, White RE, Corton C, Correia S, Ba Abdullah MM, et al. Genome diversity of Epstein-Barr virus from multiple tumor types and normal infection. J Virol. 2015;89(10):5222-37. doi:10.1128/ JVI.03614-14.

12. Niedobitek G, Young LS, Sam CK, Brooks L, Prasad U, Rickinson AB. Expression of Epstein-Barr virus genes and of lymphocyte activation molecules in undifferentiated nasopharyngeal carcinomas. Am J Pathol. 1992;140(4):879-87.

13. Dambaugh T, Hennessy K, Chamnankit L, Kieff E. U2 region of Epstein-Barr virus DNA may encode Epstein-Barr nuclear antigen 2. Proc Natl Acad Sci USA. 1984;81(23):7632-6.

14. Sample J, Young L, Martin B, Chatman T, Kieff E, Rickinson A, et al. EpsteinBarr virus types 1 and 2 differ in their EBNA-3A, EBNA-3B, and EBNA-3C genes. J Virol. 1990;64(9):4084-92.

15. Trimeche M, Bonnet C, Korbi S, Boniver J, de Leval L. Association between Epstein-Barr virus and Hodgkin's lymphoma in Belgium: a pathological and virological study. Leuk Lymphoma. 2007;48(7):1323-31. doi:10.1080/10428190701411177.

16. Klemenc P, Marin J, Soba E, Gale N, Koren S, Strojan P. Distribution of Epstein-Barr virus genotypes in throat washings, sera, peripheral blood lymphocytes and in EBV positive tumor biopsies from Slovenian patients with nasopharyngeal carcinoma. J Med Virol. 2006;78(8):1083-90. doi:10.1002/jmv.20666.

17. Young LS, Yao QY, Rooney CM, Sculley TB, Moss DJ, Rupani H, et al. New type $B$ isolates of Epstein-Barr virus from Burkitt's lymphoma and from normal individuals in endemic areas. J Gen Virol. 1987:68:2853-62. doi:10.1099/0022-1317-68-11-2853.

18. Gutierrez MI, Raj A, Spangler G, Sharma A, Hussain A, Judde JG, et al. Sequence variations in EBNA-1 may dictate restriction of tissue distribution of Epstein-Barr virus in normal and tumour cells. J Gen Virol. 1997;78:1663-70. doi:10.1099/0022-1317-78-7-1663.

19. Bhatia K, Raj A, Guitierrez MI, Judde JG, Spangler G, Venkatesh H, et al. Variation in the sequence of Epstein Barr virus nuclear antigen 1 in normal peripheral blood lymphocytes and in Burkitt's lymphomas. Oncogene. 1996;13(1):177-81.

20. Snudden DK, Smith PR, Lai D, Ng MH, Griffin BE. Alterations in the structure of the EBV nuclear antigen, EBNA1, in epithelial cell tumours. Oncogene. 1995;10(8):1545-52.

21. Chang KL, Chen YY, Chen WG, Hayashi K, Bacchi C, Bacchi M, et al. EBNA-1 gene sequences in Brazilian and American patients with Hodgkin's disease. Blood. 1999;94(1):244-50.

22. Zhang XS, Wang HH, Hu LF, Li A, Zhang RH, Mai HQ, et al. V-val subtype of Epstein-Barr virus nuclear antigen 1 preferentially exists in biopsies of nasopharyngeal carcinoma. Cancer Lett. 2004;211(1):11-8. doi:10.1016/j. canlet.2004.01.035.

23. Edwards RH, Seillier-Moiseiwitsch F, Raab-Traub N. Signature amino acid changes in latent membrane protein 1 distinguish Epstein-Barr virus strains. Virology. 1999;261(1):79-95. doi:10.1006/viro.1999.9855.
24. Li DJ, Bei JX, Mai SJ, Xu JF, Chen LZ, Zhang RH, et al. The dominance of China 1 in the spectrum of Epstein-Barr virus strains from Cantonese patients with nasopharyngeal carcinoma. J Med Virol. 2009;81(7):125360. doi:10.1002/jmv.21503.

25. Li A, Zhang XS, Jiang JH, Wang HH, Liu XQ, Pan ZG, et al. Transcriptional expression of RPMS1 in nasopharyngeal carcinoma and its oncogenic potential. Cell Cycle. 2005;4(2):304-9.

26. Brooks LA, Lear AL, Young LS, Rickinson AB. Transcripts from the EpsteinBarr virus BamHI A fragment are detectable in all three forms of virus latency. J Virol. 1993;67(6):3182-90.

27. Smith PR, de Jesus O, Turner D, Hollyoake M, Karstegl CE, Griffin BE, et al. Structure and coding content of CST (BART) family RNAs of Epstein-Barr virus. J Virol. 2000;74(7):3082-92.

28. Yamamoto T, Iwatsuki K. Diversity of Epstein-Barr virus BamHI-A rightward transcripts and their expression patterns in lytic and latent infections. J Med Microbiol. 2012;61(Pt 10):1445-53. doi:10.1099/jmm.0.044727-0.

29. Chen H, Huang J, Wu FY, Liao G, Hutt-Fletcher L, Hayward SD. Regulation of expression of the Epstein-Barr virus BamHI-A rightward transcripts. J Virol. 2005;79(3):1724-33. doi:10.1128/JVI.79.3.1724-1733.2005.

30. Hu K, Liao D, Wu W, Han AJ, Shi HJ, Wang F, et al. Targeting the anaphase-promoting complex/cyclosome (APC/C)- bromodomain containing 7 (BRD7) pathway for human osteosarcoma. Oncotarget. 2014;5(10):3088-100.

31. Marquitz AR, Raab-Traub N. The role of miRNAs and EBV BARTs in NPC. Semin Cancer Biol. 2012;22(2):166-72. doi:10.1016/j. semcancer.2011.12.001.

32. Bei JX, Jia WH, Zeng YX. Familial and large-scale case-control studies identify genes associated with nasopharyngeal carcinoma. Semin Cancer Biol. 2012;22(2):96-106. doi:10.1016/j.semcancer.2012.01.012.

33. Hildesheim A, Wang CP. Genetic predisposition factors and nasopharyngeal carcinoma risk: a review of epidemiological association studies, 2000-2011: Rosetta Stone for NPC: genetics, viral infection, and other environmental factors. Semin Cancer Biol. 2012;22(2):107-16. doi:10.1016/j.semcancer.2012.01.007.

34. Jia WH, Qin HD. Non-viral environmental risk factors for nasopharyngeal carcinoma: a systematic review. Semin Cancer Biol. 2012;22(2):117-26. doi:10.1016/j.semcancer.2012.01.009.

35. Bosch FX, Burchell AN, Schiffman M, Giuliano AR, de Sanjose S, Bruni $L$, et al. Epidemiology and natural history of human papillomavirus infections and type-specific implications in cervical neoplasia. Vaccine. 2008;26(Suppl 10):K1-16. doi:10.1016/j.vaccine.2008.05.064.

36. Doorbar J, Egawa N, Griffin H, Kranjec C, Murakami I. Human papillomavirus molecular biology and disease association. Rev Med Virol. 2015;25(suppl 1):2-23. doi:10.1002/rmv.1822.

37. Drolet M, Benard E, Boily MC, Ali H, Baandrup L, Bauer H, et al. Populationlevel impact and herd effects following human papillomavirus vaccination programmes: a systematic review and meta-analysis. Lancet Infect Dis. 2015;15(5):565-80. doi:10.1016/S1473-3099(14)71073-4

38. Coghill AE, Hsu WL, Pfeiffer RM, Juwana H, Yu KJ, Lou PJ, et al. EpsteinBarr virus serology as a potential screening marker for nasopharyngeal carcinoma among high-risk individuals from multiplex families in Taiwan. Cancer Epidemiol Biomarkers Prev. 2014;23(7):1213-9. doi:10.1158/10559965.EPI-13-1262

39. Chan KC. Plasma Epstein-Barr virus DNA as a biomarker for nasopharyngeal carcinoma. Chin J Cancer. 2014;33(12):598-603. doi:10.5732/ cjc.014.10192.

40. Al-Mozaini M, Bodelon G, Karstegl CE, Jin B, Al-Ahdal M, Farrell PJ. EpsteinBarr virus BART gene expression. J Gen Virol. 2009;90(Pt 2):307-16. doi:10.1099/vir.0.006551-0.

41. Zhang J, Chen H, Weinmaster G, Hayward SD. Epstein-Barr virus BamHi-a rightward transcript-encoded RPMS protein interacts with the CBF1-associated corepressor CIR to negatively regulate the activity of EBNA2 and NotchIC. J Virol. 2001;75(6):2946-56. doi:10.1128/JVI.75.6.2946-2956.2001.

42. Lin DC, Meng $X$, Hazawa M, Nagata $Y$, Varela AM, Xu L, et al. The genomic landscape of nasopharyngeal carcinoma. Nat Genet. 2014;46(8):866-71. doi:10.1038/ng.3006. 